\title{
工程测量中摄影测量和遥感的应用分析
}

\section{丁文利 王良民}

河南省地质矿产勘查开发局测绘地理信息院

DOI:10.32629/gmsm.v3i3.687

[摘 要] 现阶段,信息技术在各个行业的发展中得到了有效应用,摄影测量、遥感技术和现代化信息技术之间的联系十分密切,其具有稳定性、 测量周期短等优势。工程测量是工程项目建设中的基础内容和关键内容,相关部门必须予以重视,在工程测量过程中,技术人员可以利用摄影测 量和遥感技术的定位、遥感功能,优化施工准备阶段的勘察工作, 提高工程项目建设的整体质量, 降低施工成本的投入, 文章分析了工程测量中摄 影测量和遥感的应用。

[关键词]工程测量；摄影测量；遥感技术；应用

\section{引言}

在现代化社会的快速发展中, 我国摄影测量和遥感技术水平达到了很 大提升, 在工程测量中得到了有效应用, 可以在不接触的情况下针对物体 做好测量和研究工作, 通过分析各项数据获取工程项目建设所需的各项参 考信息, 提高工程测量的整体效率。基于此, 文章介绍了摄影测量和遥感技 术的相关内容, 阐述了工程测量中摄影测量和遥感的重要性, 总结了工程 测量中摄影测量和遥感的应用问题, 并对工程测量中摄影测量和遥感的应 用进行了分析。

\section{1 摄影测量及遥感技术概述}

目前, 我国综合摄影技术得到了快速发展, 摄影测量和遥感技术在不 断提升, 现有的信息技术标准平台中, 地理技术得到了有效应用, 可以整合 并形成综合信息平台的科学测量标准 ${ }^{[1]}$ 。在施工准备阶段, 工程测量工作 主要是勘查并收集地形数据信息。在传统的地形数字化、郊外实地收集测 量数据时, 需要消耗大量的人力资源、物力等, 这项工作持续时间很长, 延 误了工程项目建设的施工工期。在工程项目勘查过程中, 技术人员需要准 确、高效地获取工程建设所需原始数据, 这就使得摄影测量和遥感技术的 重要性不断显现出来, 为工程勘查工作的高效进行提供了支持。在摄影测 量和遥感技术应用过程中, 技术人员无需到施工现场进行考察, 可以通过 物体传输方式将实地数据信息传输到传感器中, 利用各项数据信息实现实 地物体测量的预期目标, 通过分析和处理获取的数据, 为后续工程建设提 供了重要的参考依据。

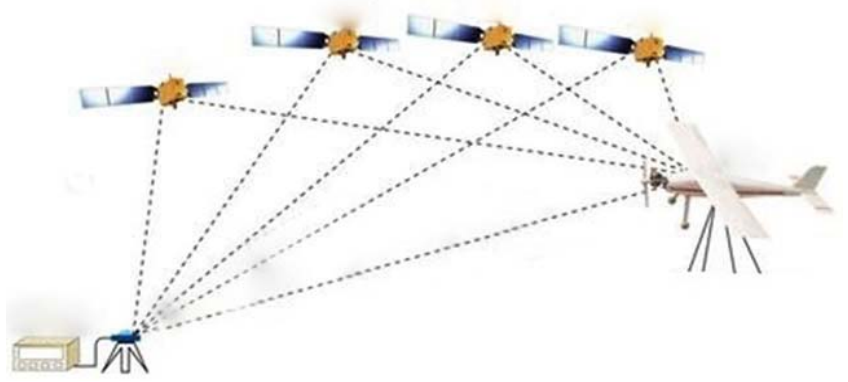

图1 摄影测量和遥感技术图

在新时期的快速发展中, 摄影测量技术水平得到了很大提升, 这项技 术主要是针对数字影像进行自动相片内定向、绝对定向、相对定向、自动 空中三角测量、匹配数字影像, 以此为基础构建高程模型, 明确正射影像、 提取地物要素, 为工程项目建设的实施提供技术支持。遥感技术通过应用 电磁波理论, 选择多个传感器辐射远距离目标、反射电磁波信号, 随后收集 并处理各项数据, 最终成像, 这项技术可以探测和识别地面多种物体, 遥感
技术的应用可以在确保质量的基础上快速测绘地图。在实际的工程测量过 程中, 技术人员需要将卫星和遥感影像进行融合, 使用卫星系统针对测量 物体进行定位, 并将各项数据传输到感应其中, 最终形成遥感图像, 如图 1 所示。另外, 技术人员可以分析遥感图像数据, 并对其进行处理, 为工程建 设提供数据支持。

\section{2 工程测量中摄影测量和遥感的重要性}

在工程项目建设中, 摄影测量和遥感技术是其中的关键技术, 发挥着 十分重要的作用。工程项目建设中存在很多影响因素, 如国家市政建设规 划、社会经济发展水平、投资资金等, 都会阻碍工程项目建设的顺利实施。 并且, 工程所在地区的气候因素、地质条件、水文环境和地质环境等, 也会 影响工程建设工作的实施。在工程测量过程中, 勘测数据为后期建设设计 提供了基础支持, 在勘查数据出现误差的情况下, 都会带来不必要的损失, 甚至威胁人民群众的生命财产安全。同时, 卫星摄影测量覆盖范围比较大, 能够改善传统测量工作的局限性, 针对动态的地质灾害进行预测, 进一步 提高工程测量的整体质量。并且, 摄影测量与遥感技术的应用节省了大量 的勘探时间, 无需在施工建设中投入大量人力资源、资金, 提高工程项目建 设的整体效率。另外, 摄影测量与遥感技术的应用为施工单位节省大量的 施工成本, 为施工单位提供了数据支持, 确保了工程项目建设的整体质量 和安全性。

\section{3 工程测量存在的问题}

3. 1测量人员专业素质有待提高

在建筑行业的快速发展中, 建筑市场对专业技术人才的需求量日益增 加, 人才紧缺问题日益严重, 建筑行业内部技术人员较少, 很多工作人员负 责多项工作, 这就为技术人员带来了很大压力, 严重影响着工程项目建设 的整体质量。现阶段, 我国检测设备、检测环境日益复杂, 工程测量技术人 员必须不断提升自身的职业素养, 工程测量属于精细化工作, 测量人员需 要确保各项数据和信息的准确性, 避免因测量偏差影响后续工程结构设计 工程, 为工程质量带来一系列影响。在社会经济的快速发展中, 测量手段日 益完善, 很多工程管理部门配备了高精度、智能化的测量仪器, 很多企业缺 乏高素质的管理人才, 无法正确操作测量仪器, 导致测量数据分析受到很 大影响, 出现了一系列测量误差, 无法有效地提升测量工作的整体效率。

3. 2 管理制度有待完善

在建筑工程项目建设规模日益扩大的背景, 各个部门之间的分工日益 复杂, 工程测量带来了很大难度, 复杂的内部结构导致工程测量工作无法 得到有效协调, 很难落实到实际工作中。同时, 测量部门之间的沟通不到位, 导致很多工种无法实现有效衔接, 在遇到各项问题时会互相推诿, 无法找 到相应的负责人 ${ }^{[2]}$ 。除此之外, 测量部门为了节省更多的成本, 无法全面落 
实相关管理工作, 为建筑施工安全管理带来了一系列安全隐患, 且管理部 门在制定测量技术管理流程过程中, 缺乏相应的规章制度进行约束, 导致 各个部门之间的工作脱节, 这就需要确保各个施工流程保持统一步调, 为 工程项目管理工作的实施提供依据, 还需要做好人力资源、物力资源的统 筹管理工作, 有效地协调施工部门之间的关系, 针对各项问题制定相应的 解决对策。

\section{4 工程测量中摄影测量和遥感技术及应用}

4. 1 工程测量中的摄影测量和遥感技术

4.1.1卫星遥感影像技术

随着社会经济的快速发展, 摄影测量与遥感技术在水利工程、通信工 程和建筑工程中得到了有效应用, 通过摄影测量和遥感技术可以勘察并分 析地质条件、水文条件和气候了解, 明确工程测量的实际情况, 获取更多有 效的数据和信息。技术人员还需要分析各项工程数据的稳定性, 验证现有 的工程标准, 充分发挥出摄影测量和遥感技术的作用。卫星遥感影像技术 主要针对各个地区的地理信息进行收集、整合、处理和保存, 利用先进的 信息技术将信息转变成影像图, 为专业人员参考和分析提供便利。除此之 外, 卫星影像遥感主要利用各项传感器收集更多信息, 并利用数字化、解析 法提取并保存有用的数据和信息, 并对各项数据和信息进行分析、传输和 管理, 这项技术还将数字图像进行了结合, 利用摄影技术获取图像转化, 实 现模拟处理的预期目标。另外, 摄影测量和遥感技术的应用具有一定的灵 活性, 图像精准、虚拟化模拟, 使用周期相对较短, 可以快速获取地理信息 内容, 现已在工程测量中得到了十分广泛的应用。

\subsection{2机载激光雷达技术}

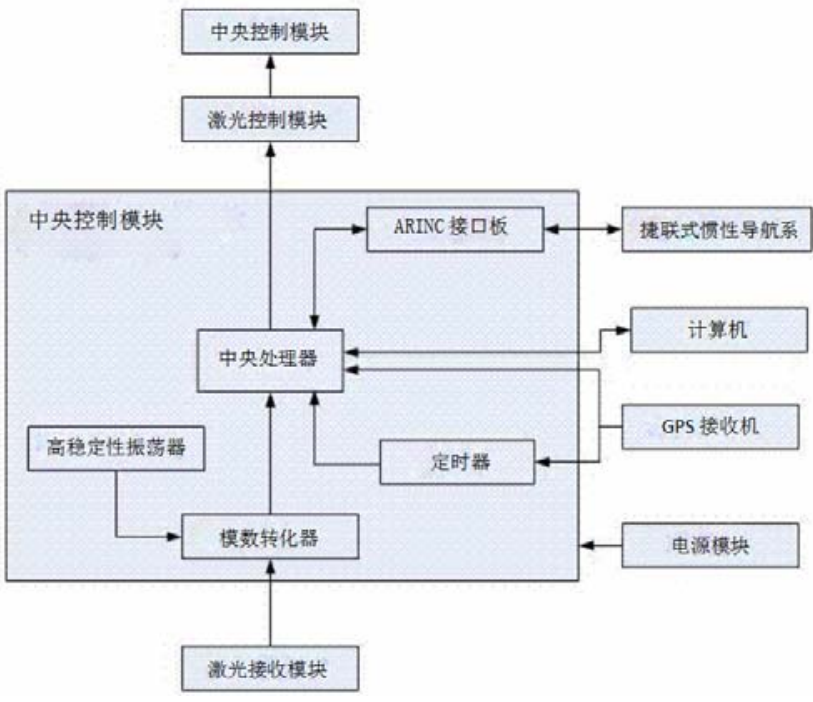

图2 机载激光雷达技术

机载激光雷达技术属于机载激光测距系统, 这项技术主要利用飞机搭 载可控激光, 由光的反射和散射波长扫描各项地理信息, 以此明确物体的 具体位置, 机载激光雷达技术将激光高度计、IMS、GPS进行了融合, 可以获 取高清的地理信息成像, 为测量技术人员获取地图三位信息提供了便利, 还有利于建立数字模型, 获取更多准确的数据和信息, 图 2 是机载激光雷达
技术图。同时, 机载激光雷达技术具有很多优势, 如测量速度快、测量范围 光、无需较多的地面勘测点, 降低了测量人员的工作量, 在很大程度上满足 了工程测量的实际要求。在工程测量过程中, 机载激光雷达技术得到了有 效应用, 不易受航空高度的影响, 可以准确地测量更多的地理信息, 为工程 项目建设工作的实施提供数据、信息支持。并且, 机载激光雷达技术的测 量范围十分广泛, 改善了传统作业局限性的影响, 能够全面做好工程现场 地面勘探工作, 获取更多有效、准确的勘探数据, 为工程项目施工设计提供 依据。另外, 机载激光雷达技术具有测量速度快、测量数据准确等优势, 在我国其他民生领域也得到了有效应用, 可以节省大量的人力资源、物力 资源, 确保测量数据的准确性, 为工程测量质量、安全性提供保障, 是现代 化工程测量中值得大力推广的一项技术。

4.2 工程测量中摄影测量和遥感的应用

4.2.1测制各种比例尺的地形图

在工程测量过程中, 常用的基本地形图比例尺有 $1: 500 、 1: 1000$ 、 $1: 2000 、 1: 5000$ 和 $1: 10000$, 使用全数字摄影测量技术可以制作各种比例尺 的数字线划图, 数据信息能够直接进入GIS系统、CAD系统中, 为工程设计提 供数据支持。

4.2.2建立影像数字地面模型和虚拟现实

数字地面模型能够反映出工程所在区域的地形、地貌情况, 对其进行 渲染可以做成设计方案景观图, 直观反映出设计意图, 利用相关软件可以 进行三维动画漫游, 展现出建筑动态施工情况, 并对建筑面积进行计算, 合 理地设定工程进度。

4.2.3制作正射影像地图

影像地形图是数字摄影测量中的重要产品, 其能够根据数字高程模型, 针对中心投影的航摄影像做好纠正处理, 可以直观、全面地反映出地物、 地貌信息, 这项技术具有成图速度快、更新周期短等优势, 为工程规划设计 和管理提供了参考 ${ }^{[3]}$ 。

\section{5 结束语}

综上所述, 在现代化社会的发展中, 摄影测量和遥感技术在工程测量 中得到了有效应用, 这项技术具有稳定性、低成本等优势, 为工程测量提供 了良好的环境支持, 通过利用摄影测量和遥感技术可以提高工程进度, 并 对其进行有效控制, 获取更多准确的工程测量数据, 为工程项目建设工作 的实施提供支持。

[参考文献]

[1]罗宇,梁晓军.浅析摄影测量与遥感在工程测量中的应用 [J].科技 创新导报,2019,16(26):21+23.

[2]海青虎.摄影测量与遥感在工程测量中的应用探究 [J].工程建设与 设计,2018,(20):279-280.

[3]白雪梅.摄影测量与遥感在工程测量中的应用探究[J].世界有色金 属,2017,(22):28+30.

作者简介：

丁文利(1975--),男,河南修武人,汉族,注册测绘师、测绘高级工程 师,从事地理信息系统建设和GPS数据处理研究。 